\title{
MULTILETRAMENTOS E CONSTRUÇÃO DE SENTIDOS EM CARTAZES PUBLICITÁRIOS DA ÁREA DA SAÚDE: UM CAMINHO DE ANÁLISE ${ }^{1}$
}

\author{
Francisco Renato Lima (UFPI) ${ }^{2}$
}

\section{RESUMO}

As imagens carregam mensagens e projetos discursivos de dizer o mundo. Comportam aspectos semânticos e sociais que podem ser lidos e interpretados de diferentes formas, de acordo com as experiências culturais particulares (os letramentos) de cada sujeito leitor. Partindo disso, objetiva-se analisar a importância dos multiletramentos (conhecimentos letrados) para a compreensão dos sentidos da imagem, tida como texto, a partir da Gramática do Design Visual (GDV). Definem-se os seguintes questionamentos: Que tipo de postura ou estratégia os sujeitos adotam nos processos de leitura e interpretação da imagem? De que forma os conhecimentos letrados (multiletramentos) interferem na compreensão dos sentidos do texto imagético? Metodologicamente, constitui-se de uma pesquisa bibliográfica de caráter qualitativo apoiada no diálogo entre teóricos como Kress e van Leeuwen (2000; 2001), autores da GDV; e teorias de letramento e multiletramentos em Dionísio (2006), New London Group (1996), Rojo (2012; 2013a; 2013b), Street (2003). O corpus de análise é constituído de duas imagens do gênero textual cartaz, ambas de uma campanha de vacinação contra a gripe, lançada nacionalmente pelo Ministério da Saúde, em 2013. A luz da GDV, as análises apontam para o processo de compreensão leitora no processo de construção de sentidos em textos imagéticos, evidenciando-se, portanto, que as diferenças nos modos de leitura dessa imagem relacionam-se aos contextos socioculturais de acesso à leitura e à escrita de cada leitor - os conhecimentos letrados ou multiletramentos -, reconhecendo-se assim, capacidades de leitura e produção de sentido que ultrapassam a mera compreensão e produção de textos escritos, mas abranjam a leitura de múltiplas semioses, as quais incluem textos em diferentes formas de linguagem, dentre eles, o imagético.

Palavras-Chave: Multiletramentos. Leitura. Textos imagéticos. Gramática do Design Visual. Construção de sentidos.

\begin{abstract}
Images carry discursive messages and projects of telling the world. They include semantic and social aspects that can be read and interpreted in different ways, according to the particular cultural experiences (the literacies) of each reader subject. From this, the objective is to analyze the importance of multi-elements (literate knowledge) for understanding the meanings of the image, taken as text, from the Visual Design Grammar (GDV). The following questions are defined: What kind of posture or strategy do the subjects adopt in the image reading and interpretation processes? How do literate knowledge (multi-skills) interfere with the understanding of the meanings of the imagery text? Methodologically, it is a qualitative bibliographical research supported by the dialogue between theorists such as Kress and van Leeuwen (2000; 2001), authors of GDV; and literacy and multi-theory theories in Dionysus (2006), New London Group (1996), Rojo (2012; 2013a; 2013b), Street (2003). The corpus of analysis consists of two images of the textual poster genre, both from a flu vaccination campaign, launched nationally by the Ministry of Health in 2013. In light of the GDV, the analyzes point to the process of reading comprehension in the process. of meaning construction in
\end{abstract}

\footnotetext{
1 Trabalho apresentado no Congresso Brasileiro Ciência e Sociedade (CBCS 2019), promovido pelo Centro Universitário Santo Agostinho, de 03 a 05 de outubro de 2019, em Teresina-PI.

${ }^{2}$ Mestre em Letras - Estudos da Linguagem. Atualmente é Professor Substituto, Classe Auxiliar, Nível - I, da Universidade Federal do Piauí (UFPI). E-mail: fcorenatolima@hotmail.com 


\section{CONGBESSO CIENCIAESOCIEDADE

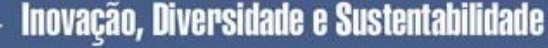

ANAIS CBCS 2019 | 3 a 5 de outubro de 2019 | Centro Universitário Santo Agostinho - Teresina - P

imagetic texts, evidencing, therefore, that the differences in the modes of reading of this image are related to the sociocultural contexts of access to reading and writing of each reader - the literate or multi-knowledge knowledge -, recognizing Thus, reading capacities and meaning production that go beyond the mere comprehension and production of written texts, but encompass the reading of multiple semioses, which include texts in different forms of language, among them, the imagetic..

Keywords: Multilevel. Reading. Texts imagery. Grammar of Visual Design. Construction of senses.

\section{CONSIDERAÇÕES INICIAIS}

Palavra e imagem são como cadeira e mesa: se você quiser se sentar à mesa, precisará de ambas. Além de tudo o mais que estiver ao redor delas. Uma vez que essa cadeira e essa mesa se encontram em um local específico, tem formato específico e foram resultado de escolhas.

(Godard (1993) apud Joly (2005, p. 115)

As imagens carregam mensagens e projetos discursivos de dizer o mundo. Comportam aspectos semânticos e sociais que podem ser lidos e interpretados de diferentes formas, de acordo com as experiências culturais particulares (os letramentos) de cada sujeito leitor. Partindo desse entendimento, este estudo objetiva analisar a importância dos multiletramentos (conhecimentos letrados) para a compreensão dos sentidos da imagem, tida como texto, a partir da Gramática do Design Visual (GDV).

Na esteira dessa compreensão, considera-se que a competência desenvolvida pelo sujeito no processo de compreensão leitora pressupõe a capacidade de produzir e interpretar gêneros variados nos mais diferentes contextos de uso interativo com a linguagem (LIMA, GOMES, 2016). Assim, tem-se uma visão de texto integrada aos fenômenos sociointerativos, que se articula aos diferentes modos de significação, construídos no curso das interações sociais.

Parte-se dos seguintes questionamentos: Que tipo de postura ou estratégia os sujeitos adotam nos processos de leitura e interpretação da imagem? De que forma os conhecimentos letrados (multiletramentos) interferem na compreensão dos sentidos do texto imagético? 
ANAIS CBCS 2019 | 3 a 5 de outubro de 2019 | Centro Universitário Santo Agostinho - Teresina - P

Do ponto de vista metodológico, constitui-se de uma pesquisa bibliográfica de caráter qualitativo apoiada no diálogo entre teóricos como Kress e van Leeuwen (1996/2001), autores da GDV e teorias de letramento e multiletramentos em Dionísio (2006), New London Group (1996), Rojo (2012; 2013a; 2013b) e Strett (2003). O corpus de análise é constituído de duas imagens do gênero textual cartaz, ambas de uma campanha de vacinação contra a gripe, lançada nacionalmente pelo Ministério da Saúde, no ano de 2013.

\section{MULTILETRAMENTOS NA LEITURA DAS IMAGENS: PERSPECTIVAS ANALÍTICAS A LUZ DA GRAMÁTICA DO DESIGN VISUAL}

Para Kress; van Leeuwen (2001), é necessário observar todas as formas de comunicação, e não somente a linguística, mas a produção de sentidos. Desse modo, uma abordagem multimodal para a compreensão textual, considera "um conjunto de modos semióticos que está sempre envolvido em toda produção dos textos" e que "tanto os produtores quanto os leitores têm poder em relação aos textos" (KRESS; LEITE-GARCIA; VAN LEEUWEN, 2000, p. 372). É nesse ponto da discussão, portanto, que se defende a importância dos conhecimentos letrados ou multiletramentos oriundos das experiências de mundo de cada leitor como fatores que interferirão na compreensão do texto (imagem), uma vez que ele também tem "poder" nessa relação.

Os sujeitos leitores, a partir da interação com o texto imagético, produzem e atribuem sentidos que são oriundos da articulação entre a materialidade desse texto imagético e os saberes socialmente produzidos nas experiências culturais de cada sujeito em seus contextos reais de circulação de conhecimentos. Conhecimentos estes que são múltiplos, plurais, fruto da convergência das diversas esferas da cultura - dominada e dominante -, o que constitui os multiletramentos e "as diversidade de linguagens que os constituem", pois "eles são interativos"; "transgridem as relações de poder [...] dos textos [verbais ou não]"; "são híbridos, fronteiriços, mestiços (de linguagens, modos, mídias e culturas)" (ROJO, 2012, p. 22-23). Nessa perspectiva, a autora ainda define multiletramentos como: 
ANAIS CBCS 2019 | 3 a 5 de outubro de 2019 | Centro Universitário Santo Agostinho - Teresina - P

Práticas de trato com os textos multimodais ou multissemióticos contemporâneos majoritariamente digitais, mas também digitais impressos - que incluem procedimentos (como gestos para ler, por exemplo) e capacidades de leitura e produção que vão muito além da compreensão e produção de textos escritos, pois incorporem a leitura e (re) produção de imagens e fotos, diagramas, gráficos e infográficos, vídeos, áudio etc. (ROJO, 2013b, p. 21)

Conforme esse entendimento, nesta etapa de análise, estabelece-se uma ponte de articulação dos aspectos teóricos até aqui tratados com a leitura das imagens, a luz dos conceitos da Gramática do Design Visual. O corpus constitui-se de duas imagens do gênero textual cartaz, ambas de uma campanha de vacinação contra a gripe, lançada nacionalmente pelo Ministério da Saúde, no ano de 2013. Os cartazes que estiveram em paredes de postos, hospitais, entre outras agências de saúde, foram coletados na internet. Ressalva-se que, embora eles sejam constituídos também de texto escrito, que apesar de ser um elemento composicional que faz parte de seu propósito comunicativo, para esta análise, o foco é apenas no texto imagético.

Figuras 1 e 2: Cartazes de campanha publicitária do Ministério da Saúde (BRASIL, 2013)
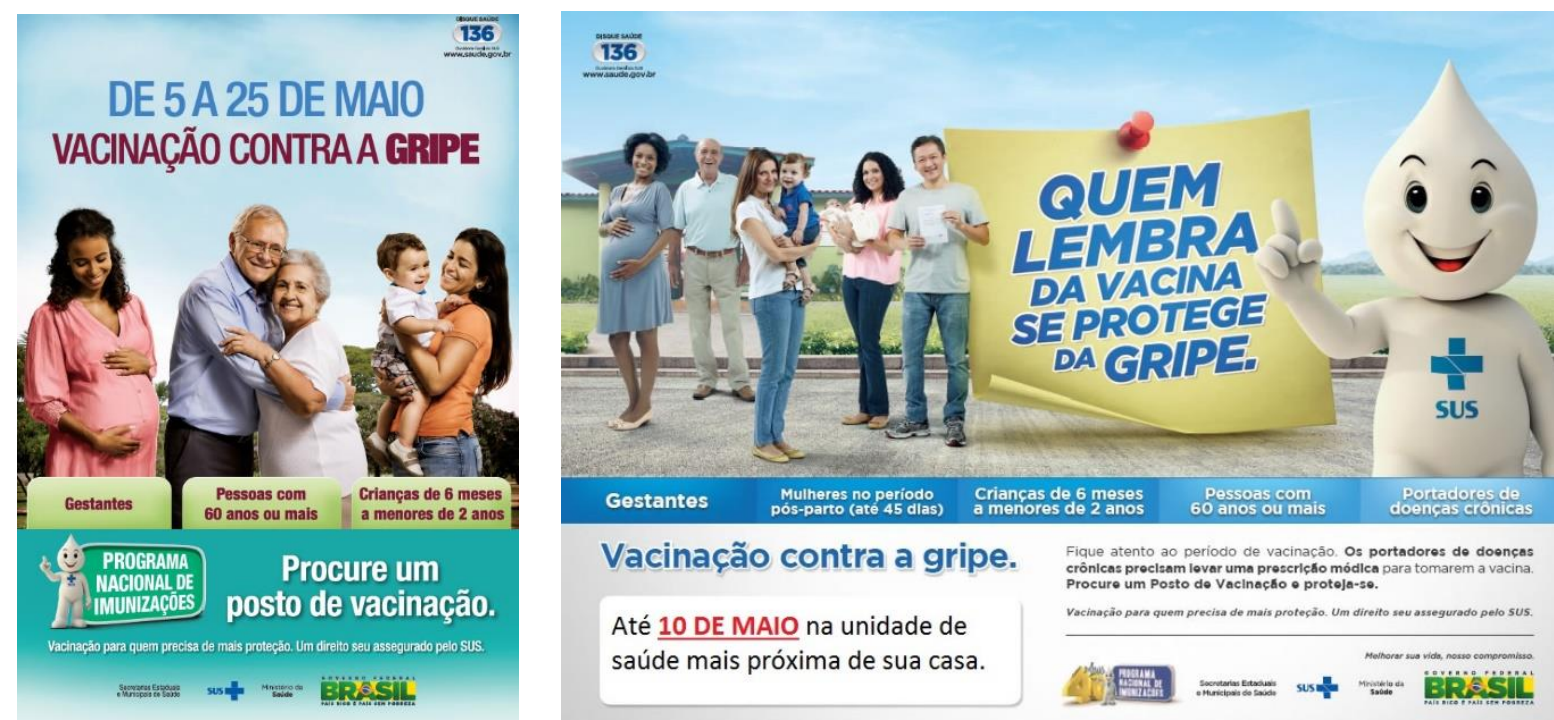

Vacinação contra a gripe.

Até 10 DE MAIO na unidade de saúde mais próxima de sua casa.

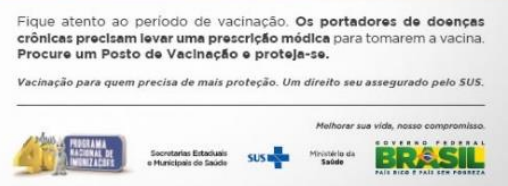

FONTE: < http://cap21.blogspot.com.br/2012/04/vacinacao-contra-influenza-tem-inicio.html > e http://cerestubaminasgerais.blogspot.com.br/2013/05/campanha-vacinacao-contra-gripe-voce.html >. Acesso em: 14 dez. 2018. 
ANAIS CBCS 2019 | 3 a 5 de outubro de 2019 | Centro Universitário Santo Agostinho - Teresina - P

A relação comunicativa entre os participantes representados nos cartazes e os espectadores (leitores) se dá a partir de um processo de interação que resulta na construção de sentidos sobre o texto imagético. A utilização de diferentes modos semióticos inter-relacionados constroem significados e sentidos, que se processam e se definem levando-se em consideração "a multiplicidade dos canais de comunicação e a crescente diversidade linguística e cultural da atualidade" (NEW LONDON GROUP, 1996, p. 60), ou seja, os conhecimentos letrados, resultantes das experiências culturais e heterogêneas do leitor.

Assim, a compreensão do texto imagético abrange um emaranhado de percepções e atitudes responsivas entre leitor e texto. Essa dimensão dialógica e interativa envolve os aspectos da cognição e da subjetividade humana, a partir das variadas percepções de mundo e do conhecimento prévio de quem lê. As formas como cada leitor interage e interpreta os textos imagéticos reflete seus contextos sócio-históricos e culturais de enunciação.

As figuras 1 e 2 fazem parte de um mesmo campo semântico-discursivo, uma vez que se trata de cartazes de campanhas publicitárias com um mesmo foco (divulgar campanhas de vacinação contra a gripe) e público-alvo (gestantes, mulheres no período pós-parto (até 45 dias), crianças de 6 meses a menores de 2 anos, pessoas com 60 anos ou mais, portadores de doenças crônicas). Nestes exemplos, é possível identificar algumas funções definidas por Kress e van Leeuwen (1996/2001) na Gramática do Design Visual (GDV).

As três metafunções estão presentes em todos os textos, apresentando-se sob perspectivas diferentes. Nas propostas de análise, geralmente não são aplicadas de modo estanque, mas articuladas, dependendo do propósito específico do leitor/analista. Neste caso, o foco é a compreensão leitora, partindo de como o leitor alcança diferentes níveis de compreensão e interação com a imagem a partir de seus conhecimentos letrados (DIONÍSIO, 2006; ROJO, 2012; 2013a; 2013b; STREET, 2003). Assim, nesta análise, consideram-se os aspectos da metafunção representacional e interativa, com o predomínio principalmente desta última, para que perceba como se desenvolve a construção de sentidos no processo da leitura do cartaz.

No primeiro cartaz (figura 1) existem três situações sendo representadas, embora os participantes de cada situação não interajam com os da outra; mas em dois destes casos, eles 
ANAIS CBCS 2019 | 3 a 5 de outubro de 2019 | Centro Universitário Santo Agostinho - Teresina - P

interagem entre si: na primeira, há uma mulher sozinha (ator), olhando para a barriga (vetor); podese dizer que interagindo com o filho (meta), pois embora seja um ser não apresentado na imagem, esteja no plano imaginário, existe uma consciência de sua existência, considerando-se um conhecimento compartilhado acerca da gravidez e de que as mães se comunicam com os filhos mesmo antes deles nascerem; e na segunda, percebe-se uma mãe (ator) que direciona o olhar (vetor) para o filho (meta) no colo, o que permite identificar, em ambos, aspectos da metafunção representacional narrativa de ação, visto que há um processo de interação entre os participantes. Nestes casos, a representação narrativa de ação é identificada principalmente pela presença dos vetores, indicando que ações estão sendo realizadas. Já a terceira situação também no mesmo cartaz retrata um casal de pessoas idosas, que embora abraçadas, não se olham entre si, olham apenas para o observador/leitor, exigindo deste uma interação, um retorno, o que remete a metafunção interativa na dimensão do olhar ou contato de demanda.

No segundo cartaz (figura 2), observa-se a perspectiva da metafunção interativa. Existem sete participantes representados, não havendo interação entre nenhum deles. Todos olham diretamente para o leitor, como a exigir-lhe algo. Até mesmo no caso das duas mulheres que estão com a criança no colo e o do rapaz que está com um papel na mão, eles não olham para suas possíveis metas (filhos e folha de papel), estão apenas apresentando-os para um expectador. Deste modo, pode-se destacar que o produtor desse texto, utilizou-se da estratégia de olhar de demanda, o que constitui uma das principais características para reconhecer a prevalência da metafunção interativa, uma vez que os participantes chamam pelo espectador, existe entre eles uma relação de cumplicidade no olhar.

Quanto aos outros aspectos de classificação das imagens, a partir dos significados da metafunção interativa, destaca-se que ambas estão em posição de plano aberto no enquadramento ou distância social do leitor, uma vez que os participantes estão representados de corpo inteiro, podendo-se situar, inclusive, o ambiente em que eles se encontram. Na figura 1, em espaços que predominam principalmente, a paisagem natural, representada pela cor verde das árvores e o azul do céu; e na figura 2, além do aspecto natural, há a presença de um edifício ao fundo e uma estrada asfaltada que serve de piso para os participantes, revelando, assim, aspectos de uma paisagem 
ANAIS CBCS 2019 | 3 a 5 de outubro de 2019 | Centro Universitário Santo Agostinho - Teresina - PI

modificada pelo homem. Nestes casos, o produtor da imagem, utiliza-se da categoria modalização, como estratégia fundamental para a construção do sentido da imagem.

No que se refere à perspectiva ou atitude em que os participantes são mostrados, na figura 1, a mulher grávida e a mulher com o bebê no colo estão em um ângulo oblíquo/subjetivo, na medida em que elas não são mostradas de frente, mas de perfil, como a esconder algo, gerando assim, menor empatia com o leitor, maior distanciamento e subjetividade; já o casal de idosos abraçados no mesmo cartaz, está em um ângulo frontal/objetiva, uma vez que encaram diretamente o leitor, mostrando-se inteiros, criando uma ideia de empatia, sinceridade e igualdade através do olhar. Já na figura 2, apenas os dois participantes adultos do sexo masculino apresentamse sob o ângulo frontal/objetivo, enquanto que as três mulheres e as crianças de colo apresentamse no ângulo oblíquo/subjetivo.

Acerca da modalidade, na qual as imagens se enquadram, destaca-se que ambas (figura 1 e 2) estão no modo natural, posto que apresentam significativa e direta relação com o mundo real, criando-se assim, um nível de verdade com a mensagem que desejam transmitir, neste caso, o alerta para a importância da vacina contra a gripe, em todas as idades.

\section{CONSIDERAÇÕES FINAIS}

A luz da GDV, as análises apontam para o processo de compreensão leitora no processo de construção de sentidos em textos imagéticos, evidenciando-se, portanto, que as diferenças nos modos de leitura dessa imagem relacionam-se aos contextos socioculturais de acesso à leitura e à escrita de cada leitor - os conhecimentos letrados ou multiletramentos -, reconhecendo-se assim, capacidades de leitura e produção de sentido que ultrapassam a mera compreensão e produção de textos escritos, mas abranjam a leitura de múltiplas semioses, as quais incluem textos em diferentes formas de linguagem, dentre eles, o imagético. 


\section{congGESSOCEENCIASSOCIEDADE \\ Inovação, Diversilialle e Sustentabiliitaale}

ANAIS CBCS 2019 | 3 a 5 de outubro de 2019 | Centro Universitário Santo Agostinho - Teresina - P

\section{REFERÊNCIAS}

DIONISIO, Angela. Gêneros multimodais e multiletramento. In: KARWOSKI, Acir; GAYDECZKA, Beatriz; BRITO, Karim (Orgs.). Gêneros textuais: reflexões e ensino. 2. ed. Rio de Janeiro: Lucerna, 2006. p. 131-144.

JOLY, Martine. Introdução à Análise da Imagem. Campinas: Papirus, 2005.

KRESS, Gunther; VAN LEEUWEN, Theo. Reading images: the Grammar of Visual Design. London: Routledge, 1996.

KRESS, Gunther; VAN LEEUWEN, Theo. Multimodal discourse: the modes and media of contemporary communication. . London: Arnold; New York: Oxford University Press, 2001.

KRESS, Gunther; LEITE-GARCIA, R.; VAN LEEUWEN, T. Semiótica discursiva. In: VAN DIJK, T. A. EI discurso como estructura y proceso: estúdios sobre el discurso. Una introducción multidisciplinaria. Compilado por Teun van Dijk. España: Gedisa, 2000.

LIMA, Francisco Renato; GOMES, Francisco Wellington Borges. Construção dos sentidos em textos imagéticos: uma interface entre multiletramentos e Gramática do Design Visual no processo de compreensão leitora. In: PINHEIRO, André; GOMES, Francisco Wellington Borges; VARÃO, Maria Goreth de Sousa; SOUZA, Tiago Barbosa (Orgs.). Linguagens, cultura e ensino: interfaces entre ficção, discurso e mídia. Teresina: EDUFPI, 2016. p. 217-244.

NEW LONDON GROUP. A Pedagogy of Multiliteracies: designing social futures. Harvard Educational Review, vol. 66, no 1, p. 60-92, 1996.

ROJO, Roxane. Escola conectada: os multiletramentos e as TICs. São Paulo: Parábola, 2013a.

ROJO, Roxane. Cenários futuros para as escolas. Cadernos Educação no Século XXI Multiletramentos (v. 3), São Paulo: Fundação Telefônica, 2013b.

ROJO, Roxane. Pedagogia dos multiletramentos. In: ROJO, Roxane; MOURA, Eduardo (Orgs.). Multiletramentos na escola. São Paulo: Parábola, 2012. p. 11-31.

STREET, Brian V. What's "new" in New Litaracy Studies? Critical approaches to literacy in theory and practice. Current Issues in Comparative Education. Comlumbia: Teachers College, Columbia Univesity, vol. 5 (2), p. 77-91, 2003. Disponível em: < http://people.ufpr.br/ clarissa/pdfs/NewlnLiteracy Street.pdf > Acesso em: 18 out. 2018. 